\title{
METODE TALAQQI ULAMA HADIS
}

\author{
Fakhrurrozi \\ Program Studi Pendidikan Bahasa Arab STAI As-Sunnah \\ Jl. Medan-Tj. Morawa, KM 13, Gg. Darmo, Desa Bangun Sari, Kab. D. Serdang, Sumut
}

\begin{abstract}
Abstrak Hadis nabi saw., berfungsi sebagai penjelas tentang kandungankandungan Alquran. Banyak permasalahan di dalam Alquran yang bersifat umum, kemudian dirinci dan diperjelas oleh hadis-hadis Nabi saw., seperti salat, zakat, puasa, haji dan lain sebagainya. Keutamaan hadis Nabi ini pula lah yang kemudian mendorong para sahabat dan ulama-ulama setelah mereka untuk berantusias mempelajari, mendalami hingga mengajarkannya kepada umat setelah mereka. Salah satu kisah menarik dalam hal ini adalah kisah Umar bin Khattab bersama salah satu tetangganya. Di mana mereka berdua saling bertukar hadis, bergantian pergi belajar dan menuntut ilmu kepada nabi saw.

Hadis-hadis nabi saw., sampai ke tangan umat belakangan melalui tangantangan para ulama. Hadis-hadis nabi tersebut berpindah-pindah dari satu tangan ke tangan yang lain. Para sahabat adalah umat yang adil. Hadis-hadis nabi di zaman mereka betul-betul murni dan terjaga. Hingga datang pertengahan abad kedua hijriah. Ketika itu, mulailah bermunculan perawi-perawi yang suka berbohong dan mengatasnamakan hadis nabi saw. Seiringan dengan keadaan itu, tumbuh pula ilmu jarh dan ta'dil. Jadi, berita yang dibawa seseorang tidak langsung diterima sehingga diperiksa hafalan dan keadilannya terlebih dahulu, riwayatnya dibanding-bandingkan dengan riwayat yang siqah bahkan mereka melakukan rihlah untuk sekedar memastikan sebuah hadis itu berasal dari sanad aslinya.
\end{abstract}

Kata Kunci: Talaqqi, Metode, Hadis

\section{A. Pembahasan}

\section{Pengertian manhaj dan Talaqqi}

Manhaj secara bahasa adalah cara atau jalan yang jelas. Sedangkan menurut istilah ialah jalan yang ditempuh untuk menemukan hakekat sesuatu dengan menggunakan kaidah-kaidah tertentu sehingga proses kerja dan berfikir lebih terarah demi tercapainya sebuah kesimpulan. ${ }^{1}$

Talaqqi secara bahasa adalah bentuk masdar dari fi'il talaqqa yang berarti bertemu, menerima atau mengambil. ${ }^{2}$ Termasuk dalam kategori ini adalah firman Allah swt., dalam surah al-Baqarah ayat 37, sebagaimana dijelaskan oleh imam at-Tabari:

\footnotetext{
${ }^{1}$ Iman Saleh al-'Ulwani, Masadir at-Talaqqi wa Usul al-Istidlal al-'Aqadiyah, (Riyad: Dar at-Tadammuriyah, 1429 H), jilid. I, h. 23.

2 'Ali al-Wahidi, al-Wasit fi Tafsir al-Qur'an al-Majid, (Libanon: Dar al-Kutub al'Ilmiyah, 1994 M), Jilid. IV, h. 195.
} 
\}َفَتَكَّى آدَمُ مِنْ رَبِّهِ كَلِمَاتِ

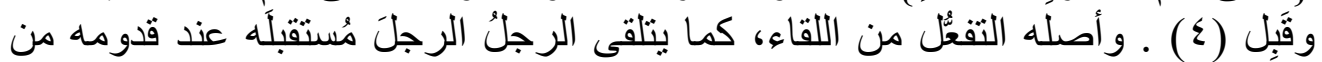

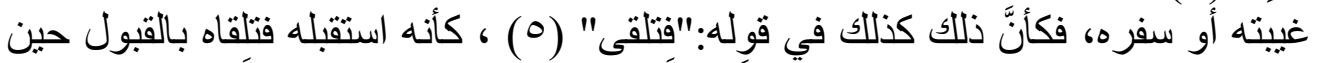

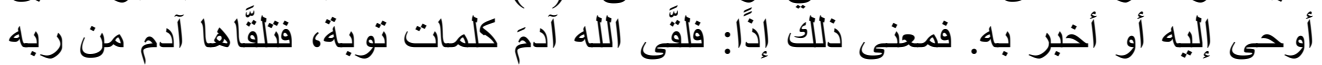
و أخذها عنه تائبًا، فتاب الله عليه بقيله إياها، وقبوله لهابه إياها من ربه.

Kemudian, setelah melakukan penelusuran terhadap makna talaqqi secara istilah, pemakalah tidak menemukan secara khusus penjelasan tentang definisi talaqqi tersebut. Tetapi kata-kata tersebut banyak digunakan ulama dalam berbagai kesempatan, khususnya tatkala mereka berbicara tentang masdar at-talaqqi. Dari beberapa penjelasan yang ditemukan maka istilah talaqqi dapat diartikan sebagai kegiatan menuntut ilmu, atau jika dikaitkan dengan materi makalah maka bisa juga dimaknai sebagai proses mengambil sebuah riwayat dari seorang guru.

Dengan demikian, maka talaqqi di sini secara sederhana adalah bagaimana ulama hadis menerima atau mengambil sebuah riwayat dari guru-guru mereka, apakah dalam penyeleksian riwayat mereka menentukan kriteria-kriteria tertentu pada guru yang menyampaikan, kemudian bagaimana metode-metode yang mereka gunakan ketika menyampaikan hadis, dan apakah hadis itu disampaikan secara lafaz atau makna?

\section{Syarat-syarat perawi}

Mengajarkan ilmu merupakan perintah Rasulullah saw., meskipun pengetahuan yang dimiliki masih dangkal dan terbatas hanya pada beberapa potong ayat atau hadis saja. Terlebih-lebih jika ditanya, maka menjadi sebuah keharusan menyampaikan ilmu tersebut, tidak boleh menutup-nutupi atau menyembunyikannya, karena agama Islam merupakan agama kebersamaan, rahmatan lil alamin, sumber ketenangan, sumber cahaya dan pedoman hidup manusia.

Hadis Nabi memiliki kedudukan yang sangat istimewa dalam agama Islam. Ia merupakan sumber kedua setelah Alquran al-Karim. Oleh karenanya, banyak orang-orang yang sengaja memanfaatkan suasana dengan cara menciptakan hadis-hadis palsu, dengan berbagai latarbelakang sebab atau kepentingan. Menyikapi hal ini, para ulama tak mau kecolongan, mereka selalu siap siaga, mencari dan menemukan solusi dari setiap masalah 
keummatan. Mereka kemudian menyusun sebuah disiplin ilmu yang belakangan dikenal dengan ilmu Hadis. Tujuan utama ilmu hadis adalah untuk menjaga keotentikan hadis-hadis nabi dari segala campur tangan atau bentuk perubahan. Setelah ulama melakukan analisis terhadap faktor-faktor yang mempengaruhi perubahan hadis tersebut, maka ditemukan dua faktor, yaitu faktor kebohongan (al-kazib) dalam periwayatan dan faktor kesalahan (alkhata').

Oleh karenanya, para ulama membuat beberapa kriteria yang harus terpenuhi pada diri seorang perawi. Bila kriteria tersebut terpenuhi maka riwayatnya diterima, bila tidak maka informasinya pun akan ditolak. Selanjutnya, untuk mencegah kebohongan maka ulama membuat uji keadilan yaitu dengan cara menetapkan kriteria tertentu, sedangkan untuk pencegahan kesalahan maka dilakukan uji kedabitan dengan menetapkan kriteria-kriteria tertentu.

\section{a. Kriteria Adil}

Syarat adil dibuat untuk menutup pintu kebohongan dalam periwayatan hadis. Para ulama telah menentukan lima kriteria seorang yang adil. Penetapan lima kriteria ini diyakini dapat menutup pintu-pintu masuknya kebohongan kepada diri seorang perawi. Berikut ini adalah syarat-syarat keadilan dimaksud:

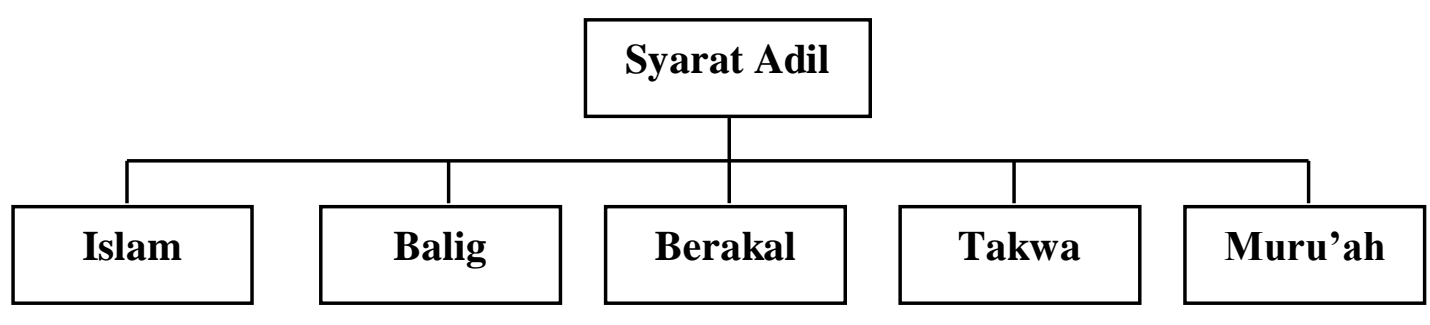

Kelima syarat adil di atas menjadi syarat mutlak yang harus terpenuhi pada diri seorang perawi. ${ }^{3}$ Riwayat orang kafir diragukan karena bisa jadi akidah kufurnya menyeretnya untuk melakukan kebohongan. Anak kecil belum mengerti sejauh mana bahaya berbohong. Yang tidak berakal juga demikian, mereka tidak menyadari ucapan yang mereka keluarkan dan sejauh mana

${ }^{3}$ Mahmud at-Tahhan, Usul at-Tahkrij wa Dirasatu al-Asanid, (Riyad: Maktabah alMa`arif, cet. III, 1996 M), h. 140-141. 
bahayanya jika mereka melakukan kebohongan. Begitu juga pelaku dosa besar, orang yang berani melakukan dosa besar bisa jadi merembet kepada dosa-dosa yang lain termasuk berbohong atas Nabi saw. Demikian juga orang yang tidak menjaga muru'ah, orang yang tidak malu terhadap masyarakat, orang-orang di sekitarnya, dikhawatirkan akan berani melakukan kebohongan, hingga atas nama Nabi saw., demikian seterusnya.

Oleh karena itu semua, maka riwayat orang kafir, anak kecil, orang gila, orang yang tidak menjaga muru'ahnya dan orang fasik selama tidak bertaubat tidak dapat diterima, karena terdapat celah yang sangat terbuka bagi mereka untuk melakukan kebohongan kepada manusia secara umum, dan besar kemungkinan hadis Nabi akan ikut menjadi korban berikutnya. ${ }^{4}$ Lima kriteria adil di atas diharapkan mampu untuk menjadi kontrol kendali bagi seseorang untuk tidak melakukan sifat-sifat buruk, termasuk sifat tidak jujur, mau berbohong dan lain sebagainya. Sehingga otentisitas hadis yang disampaikan tetap terjaga dari perubahan ataupun pemalsuan.

\section{b. Kriteria Dabit}

Dabit ialah kesetiaan ingatan seseorang terhadap sesuatu yang pernah didengarnya dari orang lain, kemudian mampu menyampaikan hafalan tersebut kembali manakala diperlukan. ${ }^{5}$ Secara umum dabit terbagi dua. Dabit secara hafalan dan dabit secara tulisan. Yang dimaksud dabit secara hafalan ialah terjaganya hadis seseorang dalam ingatannya mulai saat pertama kali diterimanya hingga ia meriwayatkannya kepada orang lain kapan saja diperlukan. Sedangkan dabit secara tulisan ialah mengingat betul hadis-hadis yang pernah ditulisnya, kemudian menjaganya dengan baik agar terhindar dari campur tangan orang lain. ${ }^{6}$

Untuk mendeteksi ke-dabit-an seorang perawi maka yang perlu dilakukan adalah uji ke-dabit-an, yaitu dengan cara membanding-bandingkan antara riwayatnya dengan riwayat orang lain yang siqah. Jika riwayatnya cocok

\footnotetext{
${ }^{4}$ Lihat Syaraf Mahmud al-Qudat, al-Minhaj al-Hadis fi 'Ulum al-Hadis, (Kuala Lumpur: Dar at-Tajdid, 2003 M), h. 41-42.

${ }^{5}$ Ramli Abdul Wahid dan Husnel Anwar Matondang, Kamus Lengkap Ilmu Hadis, (Medan: Perdana Publishing, cet. 2, 2011 M), h. 41. Lihat juga, Muhammad ibn 'Abd ar-Rahman as-Sakhawi, Fath al-Mugis bi Syar Alfiyah al-Hadis li al-'Iraqi, (Mesir: Maktabah as-Sunnah, 2003 M), jilid. II, h. 3.

${ }^{6}$ Ibid., h. 42
} 
dengan riwayat siqah lain maka biasanya orang itu dapat dikatakan sebagai seorang yang siqah, akan tetapi jika perselisihannya lebih banyak daripada persamaannya maka dapat dipastikan bahwa orang itu tidak dabit. Dengan demikian, perawi yang sering-sering tidak sejalan dengan perawi siqah lain maka riwayatnya ditolak, karena besar dugaan riwayatnya mengandung kesalahan. $^{7}$

Dari beberapa uraian di atas terlihat bahwa di antara manahij almuhaddisin dalam talaqqi adalah menetapkan beberapa kriteria pada diri seorang perawi. Hal ini dilakukan untuk mamastikan agar riwayat yang mereka sampaikan betul-betul asli, terjaga dan tidak mengalami perubahan.

\section{Penerimaan Hadis / Tahammul Hadis}

Proses pembelajaran dalam bidang hadis, mempelajari kemudian mengajarkannya kepada orang lain biasa disebut ulama hadis dengan istilah at-tahammul wa al-ada'. At-tahammul artinya menanggung sesuatu. Penggunaan kata-kata yang demikian bertujuan supaya seorang penuntut ilmu hadis benar-benar merasakan bahwa periwayatan hadis adalah amanah yang harus ditanggung dan disampaikan kepada orang yang tepat. Dengan demikian proses belajar hadis dikatakan sebagai at-tahammul, sedangkan mengajarkannya kepada orang lain disebut sebagai $a l$ - 'ada'. Jadi hampir sama dengan at-ta`alum wa at-ta lim. $^{8}$

Salah satu bentuk perhatian ulama hadis terhadap hadis nabi saw., adalah adanya beberapa metode yang mereka gunakan dalam periwayatan hadis-hadis nabi. Metode-metode tahammul riwayat tersebut diklasifikan menurut kualitasnya. Mulai dari yang terbaik hingga kepada yang terendah.

Belajar hadis dan mendengarkannya dari seorang guru berpengaruh kepada keterjagaan otentisitas hadis itu sendiri. Oleh karenanya, ulama berbeda pendapat tentang standar umur anak yang hadisnya dapat diakui dan dipertanggungjawabkan. Sebagian ulama berpendapat lima tahun, sebagian yang lain tujuh tahun dan ada juga yang mengatakan patokannya adalah

${ }^{7}$ Lihat Mahmud at-Tahhan, Taisir Mustalah al-Hadis, (Riyad: Maktabah al-Ma'arif, cet. X, 2004 M), h. 182-183.

${ }^{8}$ Syaraf Mahmud, al-Minhaj ........, h. 36. 
kesanggupan menghafal dan memahami hadis. ${ }^{9}$ Jika pendapat yang terakhir ini diambil, itu artinya tidak ada batasan tertentu, yang terpenting adalah tamyiz-nya bukan umurnya, karena kemampuan hafalan dan pemahaman anak pasti berbeda antara satu dengan yang lain.

Selanjutnya, kegiatan tahammul yang dilakukan oleh non muslim dapat diterima dan bisa dipertanggungjawabkan. Alasannya, karena kebohongan dan kesalahan baru akan terjadi pada saat periwayatan bukan saat menerimanya. Adapun saat proses pengambilan riwayat, muslim dan non muslim pada prinsipnya sama saja. Dengan demikian, riwayat yang diambil oleh perawi sebelum Islam kemudian disampaikannya setelah masuk Islam dapat diambil dan diterima. ${ }^{10}$

Proses kegiatan talaqqi atau tahammul hadis dilakukan dengan menggunakan delapan cara, sebagaimana terlihat pada gambar berikut:

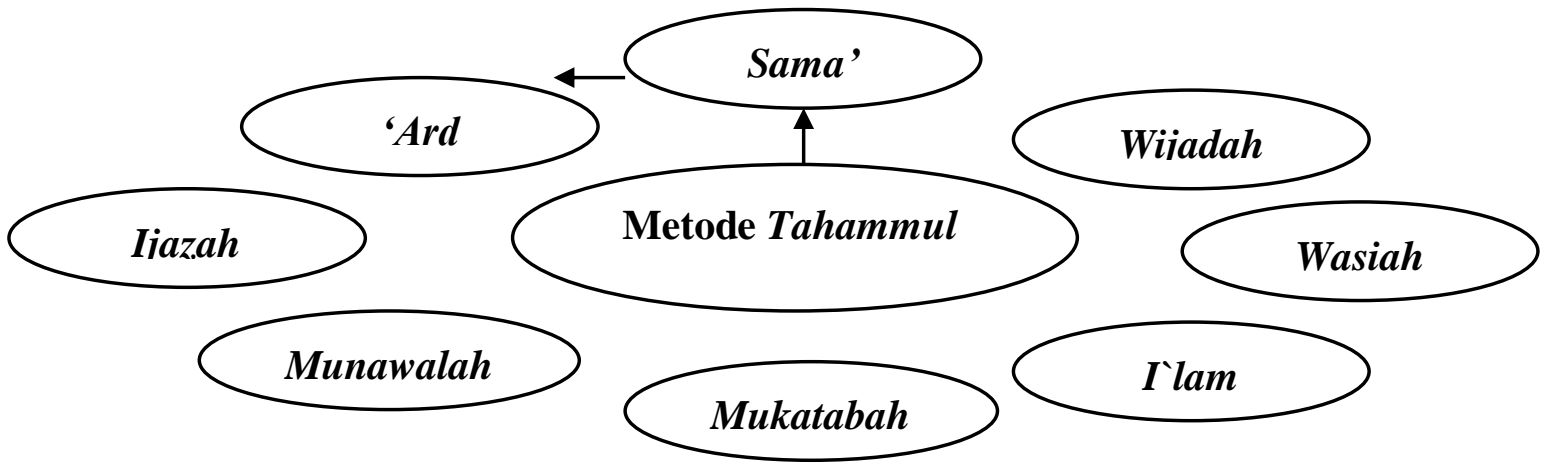

1. Metode Sama

Maksud sama` di sini ialah seorang guru meriwayatkan hadis baik dari hafalan maupun dari kitab, sedangkan murid hanya fokus mendengarkan atau bisa juga sambil mencatatnya.

Metode sama' ini banyak digunakan oleh para sahabat, bahkan kebanyakan hadis-hadis mereka diriwayatkan dengan cara ini. Oleh karenanya, menurut pendapat mayoritas ulama hadis, metode periwayatan secara sama`adalah metode paling bagus dibandingkan dengan metodemetode yang lain. ${ }^{11}$

2. Metode 'Ard

\footnotetext{
${ }^{9}$ Ibid., h. 36.

${ }^{10}$ Ibid., h. 36-37.

${ }^{11}$ Ibid., h. 37. Lihat juga Mahmud at-Tahhan, Taisir Mustalah..., h. 196.
} 
Yaitu metode tahammul hadis di mana seorang murid membacakan hadis di hadapan gurunya, baik luar kepala maupun melihat buku. Dalam hal ini guru hanya menyimak dan memperhatikan. Jika bacaan tersebut sudah benar dan diakui oleh gurunya, maka kegiatan tersebut dianggap sah sebagai salah satu metode tahammul yang diakui.

Selanjutnya, kedudukan antara sama' dengan 'ard/qira'ah masih diperselisihkan oleh ulama. Sebagian menilai kedudukannya sama saja, meskipun mayoritas tetap bertahan bahwa bobot kualitas sama lebih baik dari 'ard. ${ }^{12}$ Terlepas dari perbedaan tersebut, yang terpenting adalah mengetahui bahwa kedua metode tahammul tersebut sama-sama diakui dalam pengambilan riwayat.

\section{Metode Ijazah}

Yaitu izin atau rekomendasi untuk meriwayatkan hadis. Misalnya seorang guru mengatakan kepada muridnya, "saya izinkan kamu meriwayatkan hadis-hadis Sahih Bukhari dariku”. Menurut jumhur ulama, memberikan izin kepada murid untuk meriwayatkan kitab tertentu merupakan salah satu metode tahammul yang sah, dengan catatan naskah yang digunakan tersebut sesuai dengan aslinya atau salinannya tetapi telah dikoreksi oleh sang guru. ${ }^{13}$

\section{Medode Munawalah}

Yaitu sang guru memberikan hadis kepada muridnya dalam bentuk tulisan. Lagi-lagi menurut jumhur, metode tahammul seperti ini sah apabila disertai pernyataan izin, yakni izin atau rekomendasi dalam periwayatan hadis. Adapun munawalah yang tidak disertai rekomendasi dari guru, masih diperselisihkan di antara ulama, meskipun pendapat yang terkuat adalah sah. ${ }^{14}$ Berbeda dengan Mahmud at-Tahhan, beliau lebih membenarkan pendapat yang mengatakan tidak tidak sah jika munawalah tidak disertai izin. ${ }^{15}$

\footnotetext{
${ }^{12}$ Syaraf Mahmud, al-Minhaj al-Hadis, h. 38.

${ }^{13}$ Ibid., h. 39.

${ }^{14}$ Ibid., h. 38.

15 At-Tahhan, Taisir Mustalah al-Hadis, h. 200.
} 


\section{Metode Mukatabah}

Maksud mukatabah ialah seorang guru mengirimi muridnya surat yang isinya adalah sebagian hadis-hadisnya. Metode periwayatan seperti ini dibenarkan apabila di dalam surat tersebut terdapat rekomendasi dan naskah itu benar-benar merupakan tulisan gurunya. ${ }^{16}$

\section{Metode Ilam}

Maksudnya ialah seorang guru memberitahukan kepada muridnya bahwa hadis tertentu atau kitab tertentu merupakan bagian dari riwayatriwayatnya dari seseorang. Jika kitab atau hadis-hadis tersebut dapat dipastikan sebagai riwayat-riwayat gurunya, maka pada prinsipnya tidak ada alasan bagi siapa pun untuk menolak metode ini. ${ }^{17}$

Secara langsung memang tidak ada izin untuk meriwayatkan hadis dari sang guru. Tetapi dapat difahami bahwa pemberitahuan semacam itu secara tidak langsung mengandung pemberian izin atau rekomendasi. Namun demikian permasalahan ini tetap masih diperdebatkan di kalangan ulama. Alasan sebagian ahli hadis, bisa jadi kitab tersebut memiliki beberapa kesalahan, itu sebabnya kenapa sang guru tidak memberikan izin periwayatan $^{18}$.

\section{Metode Wasiah}

Yaitu seorang guru berwasiat, sebelum meninggal atau bepergian jauh, agar kitab-kitab riwayatnya diberikan kepada muridnya. Akan tetapi wasiat tersebut tidak disertai adanya izin atau rekomendasi. Mahmud atTahhan melihat bahwa metode seperti ini tidak dibenarkan. Alasannya karena sang guru hanya mewasiatkan bukunya tidak ada izin untuk diriwayatkan. Meskipun demikian, ada juga yang berpendapat bahwa metode ini tetap diperbolehkan dengan syarat buku-buku tersebut adalah asli tulisan gurunya sendiri. ${ }^{19}$

\section{Metode Wijadah}

\footnotetext{
${ }^{16}$ Syaraf Mahmud, al-Minhaj al-Hadis, h. 39.

${ }^{17}$ Ibid., h. 39.

${ }^{18}$ At-Tahhan, Taisir Mustalah al-Hadis, h. 202.

${ }^{19}$ Syaraf Mahmud, al-Minhaj al-Hadis, h. 39.
} 
Yaitu seorang murid menemukan sebuah hadis tulisan seseorang yang diyakininya secara pasti bahwa tulisan itu benar penisbatannya kepada orang yang bersangkutan. Misalnya, melalui kesaksian orang yang siqah atau mungkin karena kemasyhuran kitab itu ataupun dengan cara lainnnya yang menguatkan penisbatannya kepada orang tersebut. ${ }^{20}$ Metode tahammul seperti ini dinilai munqati, meskipun secara zahir ada indikasi muttasil. ${ }^{21}$

\section{Transformasi Hadis/Ada' al-Hadis}

Yang dimaksud dengan ada'u al-hadis ialah menyampaikannya kepada orang lain. Menyampaikan hadis sebagaimana telah disinggung sebelumnya harus memenuhi kriteria adil dan dabit, sehingga hadis yang disampaikan oleh perawi dapat diterima dan bisa dipertanggungjawabkan.

Seiringan dengan metode tahammul yang dipakai oleh para ulama pada saat pengambilan hadis, lahir pula lah lambang-lambang periwayatan yang mereka gunakan ketika menyampaikannya kepada orang lain. Dengan kata lain, lambang-lambang periwayatan sangat berkaitan dengan metode tahammul yang digunakan. Berikut adalah lambang-lambang yang biasa digunakan oleh para ulama dalam periwayatan hadis ${ }^{22}$ :

\begin{tabular}{|c|c|c|}
\hline ألفاظ الأداء & طريقة التحمل & 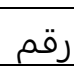 \\
\hline سمعت - حدثنا - حدثني & السماع & 1 \\
\hline أخبرنا - قر أت على فلان - حدثني قر اءة عليه & 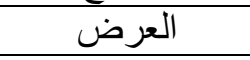 & r \\
\hline أنبأنا - ناو لني فلان - حدثنا مناولة & المناولة & $r$ \\
\hline أنبأنا - أجازني فلان - حدثنا إجازة & الإجازة & $\varepsilon$ \\
\hline كتب إلي فلان - أخبرني كتابة & 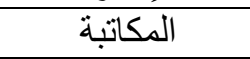 & 0 \\
\hline أعلمني فلان بكذا & الإعلام & 7 \\
\hline أوصى إلي فلان - حدثني فلان وصية & الوصية & $\mathrm{v}$ \\
\hline وجدت بخط فلان - قر أت بخط فلان كذا & 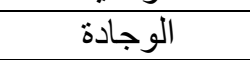 & $\wedge$ \\
\hline
\end{tabular}

Selanjutnya, perlu ditambahkan bahwa para ulama lazim menggunakan singkatan-singkatan dari sebagian lambang-lambang periwayatan di atas.

${ }^{20}$ Ibid., h. 40.

${ }^{21}$ Ibn al-Mulaqqin al-Misri, al-Muqni' $f i$ 'Ulum al-Hadis, (as-Su'udiyah: Dar Fawaz, 1413 H), jilid. I, h. 334.

${ }^{22}$ Ibid., h. 46. Mahmud at-Tahhan, Taisir Mustalah al-Hadis, h. 197-203. 
Peringkasan ini bertujuan untuk efisiensi kata-kata, lantaran seringnya digunakan secara berulang-ulang.

Haddasana (حدثا) biasanya disingkat menjadi sana (نثا), ada juga yang menyingkatnya menjadi na (نا)saja. Demikian juga lambang akhbarana (أخبرنا), disingkat menjadi $n a$ (نا), tapi ada juga yang meringkasnya menjadi ana (أنا). ${ }^{23}$

\section{Periwayatan Secara Makna}

Kemampuan manusia dalam hal hafalan pasti berbeda antara satu dengan yang lainnya. Sementara menyampaikan ilmu merupakan sebuah keharusan yang mesti dilakukan. Karena itu, para sahabat tak segan-segan mengajarkan hadis-hadis nabi meskipun tidak sama persis seperti yang disampaikan oleh nabi ketika itu. Alquran juga diturunkan sebanyak tujuh huruf/bacaan. Kisahkisah umat terdahulu juga disajikan dalam bentuk bahasa Arab, padahal umat tersebut belum tentu semuanya menggunakan bahasa Arab. Ini mengisyaratkan tentang bolehnya menyampaikan pesan secara makna. ${ }^{24}$

Berkaitan dengan hadis Nabi, menurut jumhur ulama boleh meriwayatkan hadis secara makna tetapi dengan beberapa syarat, antara lain:

1. Karena darurat disebabkan lupa atau lainnya.

2. Tidak merubah makna hadis. Konsekwensinya ialah harus mengetahui bahasa Arab dengan baik.

3. Materi hadisnya tidak berkaitan dengan bacaan-bacaan dalam ibadah tertentu di mana lafaznya sudah baku atau hadisnya bersifat jawami $u l$ kalim. ${ }^{25}$

Dengan demikian, dapat dikatakan bahwa periwayatan hadis secara makna, diperbolehkan bagi mereka yang memenuhi syarat antara lain orang yang lupa teks hadisnya dan memahami maksud hadis tersebut dengan baik. Hal ini dimaksudkan agar makna asli dari hadis itu tidak berubah. Namun

\footnotetext{
${ }^{23}$ Syaraf Mahmud, al-Minhaj al-Hadis, h. 46.

24 'Abd ar-Rahman al-Yamani, al-Anwar al-Kasyifah, (Beirut: Al-Matba`ah as-Salafiyah, 1986 M), h. 75-76.

${ }^{25}$ Syaraf Mahmud, al-Minhaj al-Hadis, h. 46-47. Lihat juga Nawir Yuslem, Ulumul Hadis, (ttp: PT. Mutiara Sumber Widya, 2010 M), h. 165-170.
} 
begitu, sebagai sikap santun terhadap nabi saw., perlu menyisipkan kata-kata, "atau sebagaimana sabda nabi saw." di ujung hadis yang sedang dibawakan.

Pada prakteknya, para sahabat dan tabiin serta ahli-ahli hadis setelah mereka tidak beralih dari redaksi aslinya kecuali berkenaan dengan keterangan mengenai keadaan peperangan atau peristiwa tertentu. Para sahabat, tabiin dan ahli hadis sesudah mereka sangat berhati-hati dalam meriwayatkan hadis dan setelah meriwayatkan sebuah hadis mereka mengatakan: atau seperti yang disabdakan Nabi (au kama qala), atau ungkapan sejenis (au nahwa haza) atau ungkapan yang serupa (au syibhahu) seperti yang diungkapkan oleh Ibn Mas`ud, Abu ad-Darda', Anas Ibn Malik dan lain-lain. ${ }^{26}$

\section{Simpulan}

Dari beberapa uraian di atas, dapat disimpulkan bahwa terdapat beberapa metode ulama hadis dalam talaqqi hadis. Antara lain mereka menetapkan beberapa kriteria tentang diri seorang perawi. Hal ini mereka tetapkan dengan tujuan agar hadis-hadis yang mereka terima itu benar-benar akurat dan bisa dipertanggungjawabkan. Selain itu, dalam hal menerima dan menyampaikan hadis, mereka juga punya beberapa cara atau metode. Masing-masing memiliki arti dan kedudukan tersendiri, bahkan metode-metode tersebut berimplikasi kepada kebersambungan sanad hadis. Perhatian ulama untuk menghafal hadis juga sangat besar, tetapi tidak semua mereka sanggup menyampaikannya secara lafal, oleh karenanya ada semacam dispensasi atau keringanan untuk menyampaikan hadis secara makna bilamana syarat-syarat dan ketentuannya dipenuhi, sebagaimana telah diulas pada pembahasan.

26 'Ajjaj al-Khatib, as-Sunnah Qabla at-Tadwin, (Beirut: Dar al-Fikri, 1971 M), h. 130. 


\section{Pustaka Acuan}

Al-'Ulwani, Iman Saleh, Masadir at-Talaqqi wa Usul al-Istidlal al-'Aqadiyah, Riyad: Dar at-Tadammuriyah, $1429 \mathrm{H}$.

Al-Wahidi, 'Ali, al-Wasit fi Tafsir al-Qur'an al-Majid, Libanon: Dar al-Kutub al'Ilmiyah, 1994 M.

Al-Misri, Ibn al-Mulaqqin, al-Muqni' $f i$ 'Ulum al-Hadis, as-Su`udiyah: Dar Fawaz, 1413 H.

As-Sakhawi, Muhammad ibn 'Abd ar-Rahman, Fath al-Mugis bi Syar Alfiyah alHadis li al- 'Iraqi, Mesir: Maktabah as-Sunnah, 2003 M.

Al-Qudat, Syaraf Mahmud, al-Minhaj al-Hadis fi 'Ulum al-Hadis, Kuala Lumpur: Dar at-Tajdid, $2003 \mathrm{M}$.

At-Tahhan, Mahmud, Taisir Mustalah al-Hadis, Riyad: Maktabah al-Ma'arif, cet. X, $2004 \mathrm{M}$.

Usul at-Tahkrij wa Dirasatu al-Asanid, (Riyad: Maktabah alMa`arif, cet. III, 1996 M), h. 140-141.

Al-Yamani, 'Abd ar-Rahman, al-Anwar al-Kasyifah, Beirut: Al-Matba`ah asSalafiyah, 1986 M.

Wahid, Ramli Abdul dan Matondang, Husnel Anwar, Kamus Lengkap Ilmu Hadis, Medan: Perdana Publishing.

Yuslem, Nawir, Ulumul Hadis, ttp: PT. Mutiara Sumber Widya, 2010 M. 